\title{
USO DE VANT COMO FERRAMENTA AUXILIAR NA GESTÃO INTEGRADA DE ATERROS SANITÁRIOS
}

Caio César de Sousa Mello - caiocsmello@gmail.com

Universidade Federal de Minas Gerais

Daniel Henrique Carneiro Salim - danielhcsalim@ gmail.com

Universidade Federal de Minas Gerais

Luiza Procópio Tostes Teixeira - luizaprocopio@ gmail.com

Universidade Federal de Minas Gerais 


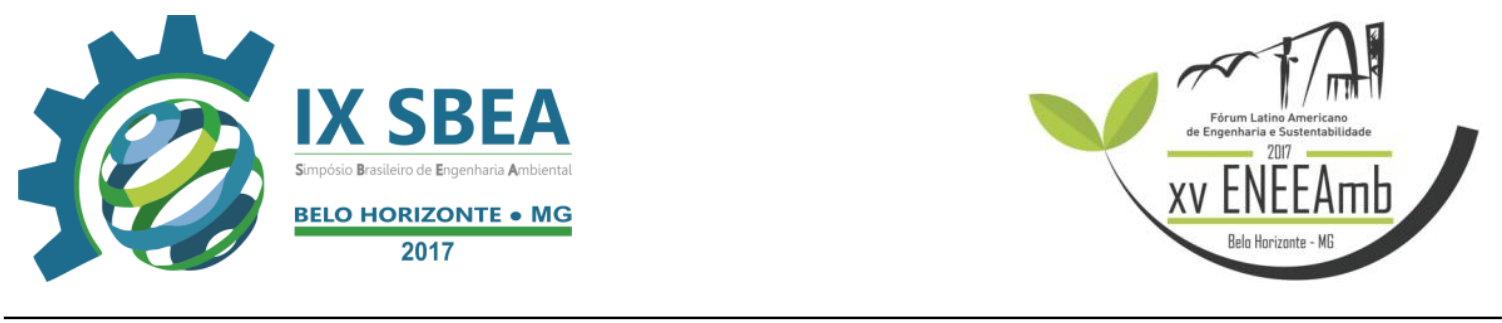

\section{RESUMO}

O conjunto de atividades de planejamento, gestão e operação de um aterro sanitário tornam-se complexas e trabalhosas visto a quantidade significativa de resíduos dispostos nos mesmos. Neste contexto, as geotecnologias são ferramentas capazes de auxiliar as tomadas de decisões no que tange desde a etapa de projeto, até o monitoramento após encerramento das atividades do mesmo. O mapeamento aéreo utilizando VANTs surge no âmbito das geotecnologias como uma alternativa de baixo custo à aerofotogrametria e à fotointerpretação, gerando produtos de alta resolução espacial e proporcionando economia de recursos financeiros, humanos e naturais, rapidez na geração de resultados, incremento de segurança no trabalho, e principalmente, por geração e coleta de dados confiáveis e de fácil compreensão, que retratam fielmente a realidade.

Palavras-chave: Aterro sanitário, VANTs, Gestão Integrada, Monitoramento Ambiental, Monitoramento Operacional, Aerofotogrametria, Fotointerpretação.

\section{INTRODUÇÃO/OBJETIVO}

O panorama realizado pela Associação Brasileira de Empresas de Limpeza Pública e Resíduos Especiais (ABRELPE) em 2015 revela que a geração de resíduos sólidos urbanos (RSU) no Brasil atingiu cerca de 80 milhões de toneladas, sendo 53\% desse montante destinado para aterros sanitários.

\subsection{Atividades operacionais e de manutenção em aterros sanitários}

A NBR 8419 descreve o aterro sanitário como uma disposição de resíduos no solo, utilizando de técnicas de engenharia para confiná-los à menor área possível e menor volume permissível, sem causar danos à saúde pública e à sua segurança, minimizando os impactos ambientais.

As etapas que compõem a consolidação de um aterro sanitário vão desde o planejamento, instalação e operação, até seu fechamento e descomissionamento, todas essas acompanhadas por manutenção e monitoramento periódicos. Dentro de tais etapas realizam-se atividades de terraplanagem e compactação de solo, manejo e compactação de resíduos, acondicionamento e impermeabilização de células, entre outros. 
A gestão integrada das atividades do aterro, visando o planejamento sustentável e seguro das atividades de construção, operação, manutenção e monitoramento do mesmo, requer uma composição multidisciplinar de equipe. Nesse contexto pode-se afirmar que a qualidade do aterro é função de três macroconjuntos de parâmetros, relativos à qualidade do local, à infraestrutura instalada e aos procedimentos operacionais adotados (CREA/PR, 2009).

\subsection{Geotecnologias e aquisição de dados por veículos aéreos não tripulados}

As geotecnologias são tecnologias desenvolvidas com a função de coletar e processar dados de posicionamento geográfico, possibilitando análises complexas através da integração de diferentes informações em um mesmo banco de dados. Dentro das geotecnologias, a fotogrametria se ocupa em analisar e obter dados quantitativos a partir de fotografias aéreas e mapas, como coordenadas, áreas, distâncias, volumes, etc. Enquanto no sensoriamento remoto são obtidos dados qualitativos a partir da análise de fotografias, mapas e imagens de satélite, denominados fotointerpretação (Tommaselli, 2009).

Dentre as vantagens dos mapeamentos aerofotogramétricos, podemos destacar que (Tommaselli, 2009): não há contato com o objeto medido, rápida aquisição de dados, riqueza de informações semânticas e geométricas nos mapeamentos, representatividade legal das fotos à época de sua tomada, possiblidade de medição de movimentos e deformações a qualquer momento que se desejar, precisão ajustável por projeto.

Tem-se difundido cada vez mais o uso de veículos aéreos não tripulados (VANTs) para realização de mapeamentos a partir de fotografias aéreas. Segundo Eisebeiss (2011), VANTs podem ser usados como plataformas de mapeamento, equipados com sistemas fotogramétricos de medições, sistemas de localização geográfica, georreferenciamento de dados, câmeras de alta resolução e outros sensorescâmeras multiespectrais, infravermelho, termais - a depender dos objetivos do mapeamento. A grande vantagem dessa ferramenta, quando comparada aos sistemas tripulados, é sua possibilidade de voar, remotamente, sobre áreas de difícil acesso, com garantia de segurança aos operadores. 


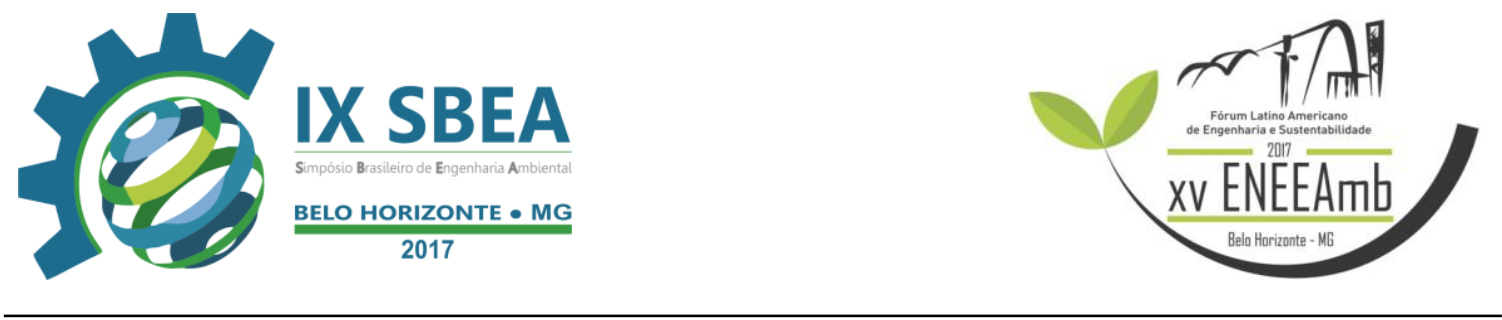

\subsection{Usos e aplicações da tecnologia}

A difusão dessa tecnologia e sua consolidação como ferramenta no suporte de tomada de decisões, registros imagéticos e monitoramento são notavelmente plausíveis, visto as vantagens já discutidas alinhadas às mais diversas aplicabilidades e à confiabilidade do método.

Como respaldo a essa afirmação, foi estabelecido um memorando (MEMO $\left.n^{\circ} 01 / 2017\right)$ pela superintendência do Departamento Nacional de Produção Mineral (SUPRIN/DNPM/MG) em janeiro de 2017, que prevê possibilidade do uso de imagens aéreas e mapeamentos de alta resolução como substituição de vistoria in loco. Tal fato pode ser encarado como uma tendência do uso desse tipo mapeamento nos mais diversos campos que exigem fiscalização, atuando como ferramenta de auxílio, por exemplo, em processos de licenciamento ambiental.

Neste cenário, esse trabalho tem como objetivo estudar as aplicações do uso da fotogrametria como ferramenta para auxiliar em todas as atividades do aterro sanitário, desde a sua concepção até monitoramento após o encerramento de suas atividades.

\section{METODOLOGIA}

\section{1. Área de estudo}

O seguinte trabalho foi realizado em um aterro sanitário na Região Sudeste do Brasil. A área de estudo do aterro é de 2,3 ha, e recebe resíduos classe I após um tratamento prévio, como autoclave.

\subsection{Material}

Para o mapeamento do aterro foi utilizado o VANT Phantom 4 Pro, desenvolvido pela DJI. Tal drone é um quadricóptero, com autonomia de voo de 30 minutos, podendo atingir velocidade de até $50 \mathrm{~km} / \mathrm{h}$ (DJI, 2017). Possui uma câmera acoplada com sensor de 20 megapixels, garantindo uma boa resolução espacial, podendo ser igual ou inferior a $5 \mathrm{~cm} /$ pixel, dependendo das características do voo, além de também desempenhar função de voo inteligente.

\subsection{Planejamento de voo}




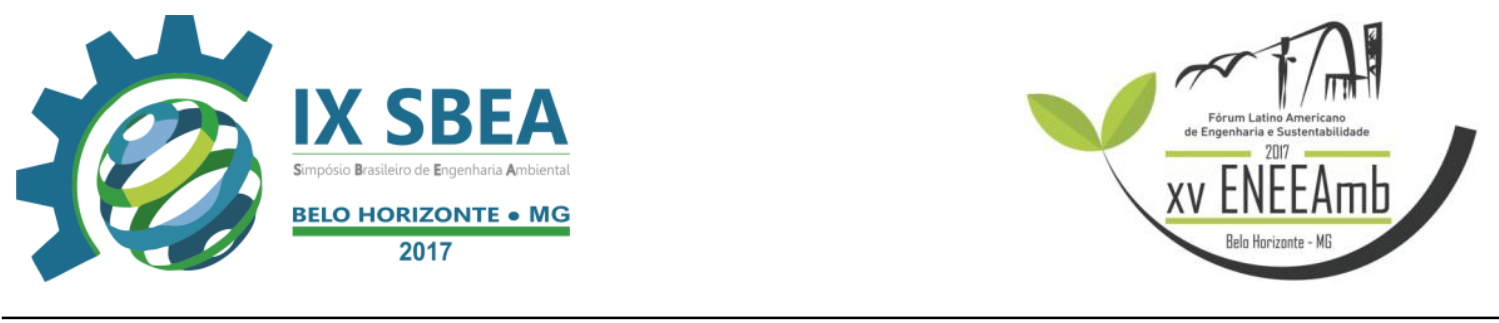

O mapeamento de uma área requer as etapas de planejamento e execução de voo e o processamento dos dados obtidos. O planejamento foi realizado pelo software Ground Station PRO, criado pela própria DJI, com os parâmetros de entrada especificados na Tabela 1 .

Tabela 1 - Parâmetros de entrada para planejamento de voo do aterro.

\begin{tabular}{|c|c|c|c|c|c|c|}
\hline \multirow{2}{*}{$\begin{array}{l}\text { Tempo } \\
\text { de voo } \\
(\min )\end{array}$} & \multirow[t]{2}{*}{$\begin{array}{l}\text { Altitude } \\
\text { (m) }\end{array}$} & \multirow[t]{2}{*}{$\begin{array}{l}\text { Velocidade } \\
\text { (m/s) }\end{array}$} & \multicolumn{2}{|c|}{$\begin{array}{c}\text { Sobreposição } \\
\text { (\%) }\end{array}$} & \multirow[t]{2}{*}{$\begin{array}{l}\text { Número } \\
\text { de fotos }\end{array}$} & \multirow{2}{*}{$\begin{array}{c}\text { Resolução } \\
\text { espacial } \\
\text { (cm/pixel) }\end{array}$} \\
\hline & & & Lateral & Vertical & & \\
\hline 11 & 46,5 & 5,6 & 85 & 80 & 247 & 1,6 \\
\hline
\end{tabular}

\subsection{Processamento das fotos}

O processamento das fotos realizou-se através do DroneDeploy, plataforma online de processamento e análise de imagens. O fluxo do processamento das imagens consiste em três etapas principais. O primeiro deles é o alinhamento das imagens, que utiliza um algoritmo de identificação de pontos comuns, permitindo fazer a orientação relativa das fotografias para um sistema de coordenadas tridimensional arbitrário. Neste processo, é gerada uma nuvem de pontos esparsa e é efetuada a autocalibração da câmera. Na segunda etapa, é construída uma nuvem de pontos densa, que cria milhares de pontos que permitem determinar informações de profundidade e preenchimento da nuvem esparsa da primeira etapa. A última fase consiste na construção do modelo 3D, onde os pontos da nuvem densa são ligados, utilizando algoritmos de triangulação. (MOUTINHO et al., 2015).

\section{RESULTADOS E DISCUSSÃO}

Todas as etapas citadas anteriormente foram utilizadas para gerar conjuntamente o modelo tridimensional (Figuras 1), a ortofoto (Figura 2.a), o modelo digital de elevação (MDE) (Figura 2.b) e, através da técnica de composição de bandas espectrais, o índice de vegetação "False Normalized Difference Vegetation Index" (Figura 2.c). 


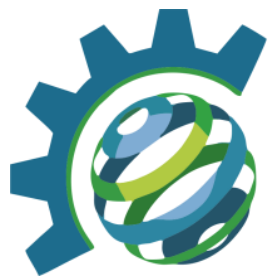

IX SBEA

BELO HORIZONTE • MG

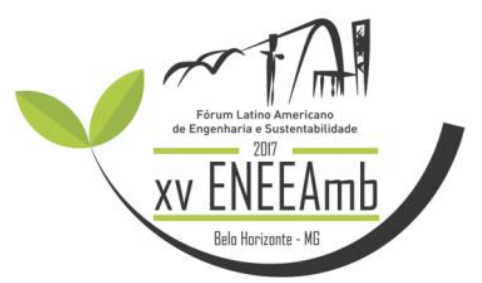

Para exemplificar a discussão abordada nos próximos itens, compilou-se um conjunto de imagens obtidas através do zoom nas ortofotos e no modelo de elevação (Figura 3).
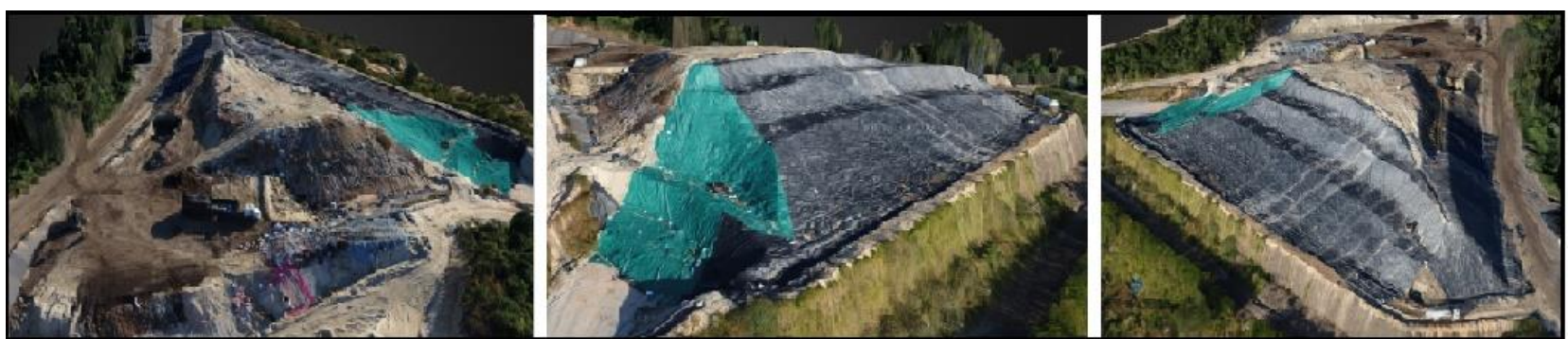

Figura 1 - Vistas do aterro pelo modelo tridimensional

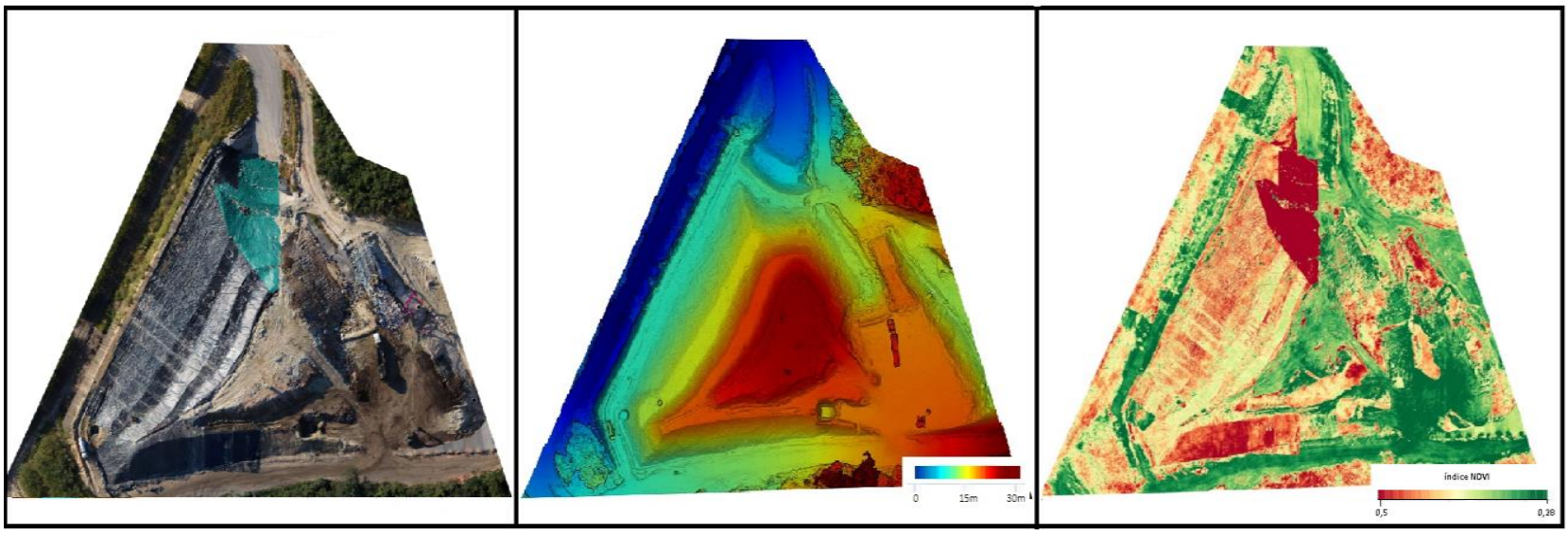

Figura 2 - (a) Ortofoto, (b) Modelo digital de elevação, (c) aplicação NDVI, respectivamente.
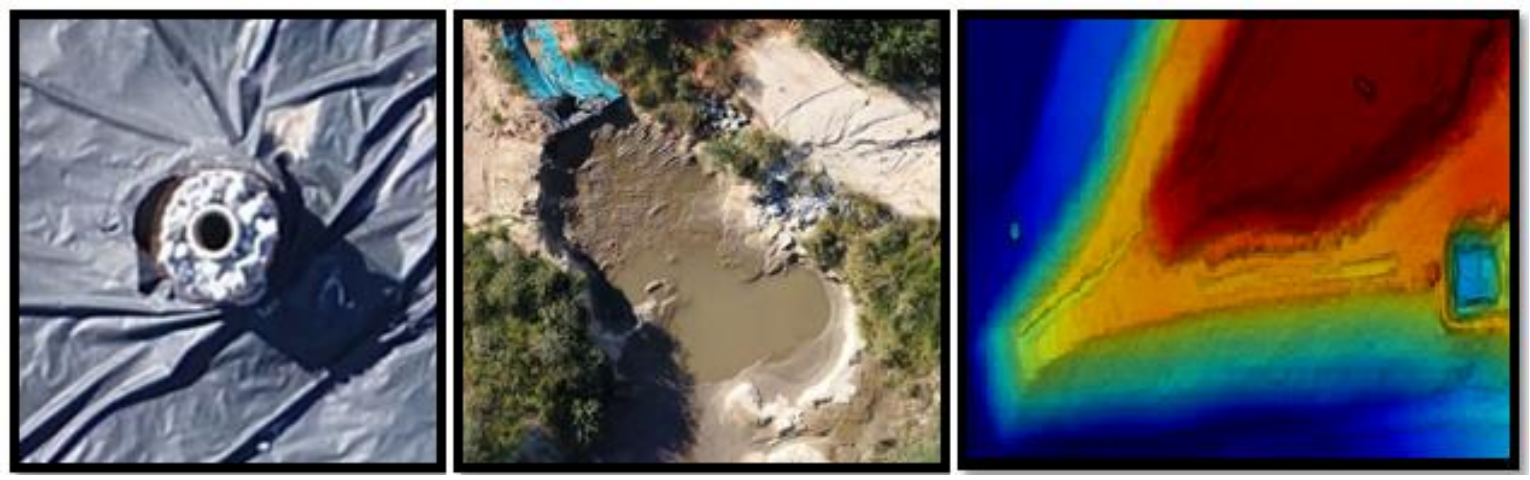

Figura 3 - Zoom de: (a) duto de ventilação, (b) dispositivo de drenagem e (c) elevação do maciço, respectivamente.

\subsection{Monitoramento e acompanhamento de aterro sanitário}

Um aterro sanitário em operação deve ser continuamente monitorado, desde a sua implantação até anos após o encerramento das atividades. O uso de ortofotos é um 


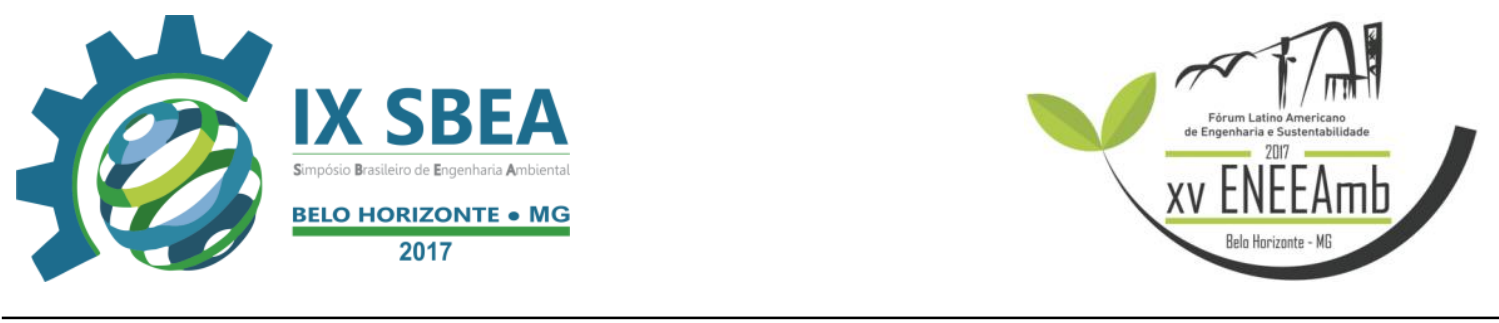

facilitador para o processo, pois a frequência do mapeamento é irrestrita, pode ser diária ou anual, e o nível de detalhamento alcança resoluções de menos de 5 centímetros por pixel, auxilia na identificação de problemas geotécnicos e de escoamento superficial no maciço. Nesse sentido, o acompanhamento frequente auxilia no registro histórico das mudanças e evoluções que ocorreram em um aterro, por exemplo, fornecendo dados que evidenciam quando e como se deu os fechamentos de células. O mapeamento frequente também pode ser inserido ao diário de obras, tornando-o mais completo e inteligível, além de agregar maior confiabilidade e valor estético. Outro exemplo, é o acompanhamento da deterioração e envergamento nos dutos de ventilação, que geralmente são causados por erosão ou assentamento do aterro (CREA/PR, 2009). Ressalta-se que o objetivo principal do aterro é reduzir os impactos ambientais provenientes de resíduos em destinação final, e quanto mais integralizado forem o monitoramento e as medidas de prevenção, há uma tendência de menor impacto ambiental.

O monitoramento geotécnico permite avaliar continuamente as questões de segurança no aterro, além de contribuir na estimativa de vida útil de suas células, sendo uma atividade imprescindível devido à constante degradação e deformação dos resíduos no decorrer do tempo (LANGE et. al., 2008). Por conseguinte, os modelos tridimensionais e de elevação gerados são ferramentas que podem nutrir substancialmente as análises técnicas, pois guardam informações relativas a topografia, e o mais exclusivo, fornecem uma visão aérea e holística sobre a área. De posse dessas informações, os tomadores de decisões possuem dados mais reais e palatáveis para fiscalização, projeção, dimensionamento e expansão de aterros sanitários. Para análises de segurança dos movimentos horizontais e verticais do maciço, recomenda-se o processamento com pontos de controle coletados com coordenadas geodésicas, pois assim, os resultados terão precisão necessária para esse tipo de diagnóstico, e terá um tempo de trabalho mais curto e menor custo profissional se comparado com a topografia convencional, conforme a Tabela 2, adaptada de um estudo de caso que mapeou uma área de 3,1 hectares (DronEng, 2016). 


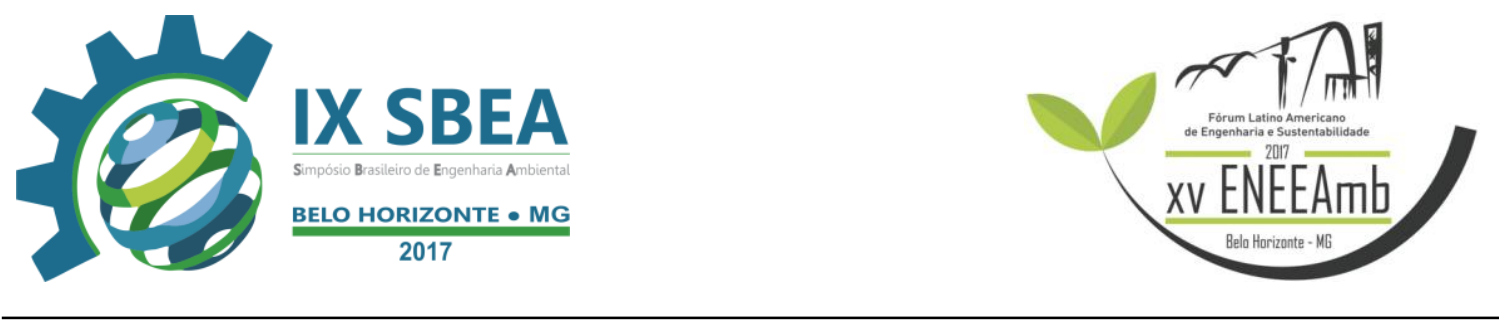

Tabela 2 - Adaptada de: Case técnico: Topografia x Fotogrametria. DronEng, 2016

\begin{tabular}{|c|c|c|c|c|}
\hline \multicolumn{5}{|c|}{ Comparativo de desempenho } \\
\hline Tipo de serviço & Tempo em Campo (h) & Tempo em Escritório (h) & Profissionais envolvidos & Nuvem de Pontos \\
\hline Topografia & 8,25 & 2,5 & 5 & 628 \\
\hline Aerofotogrametria & 0,5 & 5,1 & 3 & 1000000 \\
\hline
\end{tabular}

A ortofoto gerada no processamento é georreferenciada, portanto, pode auxiliar em diversos estudos e modelagens ambientais necessárias num aterro. Por exemplo, para monitorar vazamentos de percolados, há uma distribuição estratégica dos pontos de amostragens onde os poços serão perfurados. Nesse viés, a ortofoto e o modelo tridimensional de alta resolução podem ser usados para alimentar os dados de entrada nas modelagens do sistema pedohidrogeológico, como a coordenada e altitude de um ponto de amostragem. Além disso, a visão holística da área proporcionada pela ortofoto oportuniza um maior entendimento do local, por conseguinte, fornece mais dados para a escolha da localização dos pontos de amostragens. Para mais, essa prática também auxilia no inventário e modelagens de gases atmosféricos, que têm como dado de entrada as coordenadas das emissões pontuais, principalmente as tubulações para escape de gases, e emissões difusas, sobre toda a área superficial do aterro.

A perspectiva de análise da superfície por fotointerpretação torna-se importante pois está relacionada com a infiltração de líquidos no maciço, a proliferação de vetores e odores, a exposição dos resíduos, a dispersão de particulados e o escape descontrolado de gases para a atmosfera. Todos os impactos ambientais citados acima podem ser minimizados com monitoramento periódico da cobertura do aterro em operação ou já selados (LANGE et. al., 2008). Além disso, solos descampados podem conferir caminhos preferenciais de infiltração e percolação, elevando o risco geotécnico no aterro, ou alterar a dinâmica de escoamento superficial e erosão. Sendo assim, é uma ferramenta poderosa para inspeção e planejamento de sistemas de drenagem no próprio maciço e no entorno do aterro.

\subsection{Composição colorida de bandas espectrais}

A composição colorida de bandas espectrais se dá por operações aritméticas entre diferentes faixas espectrais, tendo como objetivo realçar alvos com respostas espectrais específicas (Santos, 2010). Esse procedimento permite avaliar, em termos 
quantitativos e qualitativos, as coberturas vegetais e sintéticas, devido a resposta espectral de um solo descampado ser diferente a de um solo coberto com vegetação ou geossintético. Sendo assim, é possível identificar fendas e acúmulos de sedimentos nas coberturas geossintéticas, como também falhas de plantio ou crescimento de vegetações. Para mais, recomendam-se as técnicas de sensoriamento remoto de classificação de áreas para análises quantitativas.

\subsection{Concepção de planos de contingência/emergência}

Os produtos gerados do processamento auxiliam na elaboração dos planos de emergência, que dão as diretrizes de procedimentos caso ocorra algum incêndio, vazamento de percolado e gases, inundações, erosões e fissuras superficiais, desmoronamento, entre outros (CREA/PR, 2009). Em caso de movimentação brusca do maciço e consequente desmoronamento, deslocamentos de taludes de fundação ou incêndios sem controle, a primeira medida de emergência é a evacuação da área através de uma rota de fuga pré-estabelecida, bem informada e sinalizada (Batista, 2010). A ortofoto e o modelo tridimensional geram dados a serem utilizados no planejamento dessa rota, como também na transferência de informações para os funcionários e visitantes do aterro sanitário.

\subsection{Plano de descomissionamento de aterros sanitários}

As aplicações citadas no tópico de monitoramento durante a operação são válidas para o monitoramento após o seu encerramento. No entanto, o modelo tridimensional e a nuvem de pontos gerada podem ser manipulados em programas de computação gráfica de renderização $2 \mathrm{D}$ e $3 \mathrm{D}$, geralmente utilizados para projetar estruturas arquitetônicas e de construção civil, tais como Sketchup e Autodesk 3dsMAX. Essa prática, apesar de pouco difundida na engenharia ambiental, tem um grande potencial de comunicação, visualização de projetos futuros e diversas simulações (Paar, 2006). A título de exemplo, supondo que exista a intenção de construir uma praça após o fechamento de um aterro, pode-se criar um ambiente virtual ilustrativo, tendo como dado de entrada o modelo tridimensional gerado anteriormente. É factível, para projeções futuras da área, a inserção de objetos, tais como árvores, bancos, banheiros, bebedouros, pessoas caminhando, entre outros. Essa estratégia é crucial para tomadas de decisões em projetos de descomissionamento. 


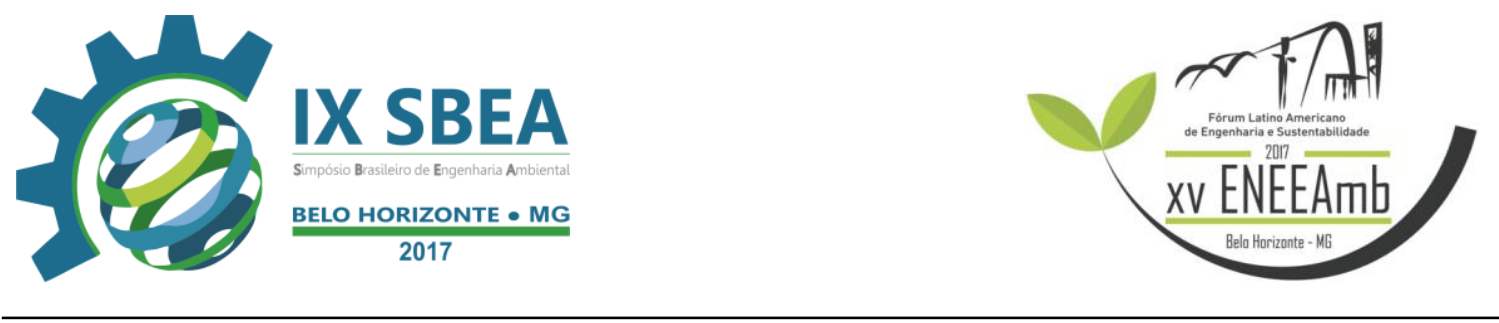

\section{CONCLUSÕES/RECOMENDAÇÕES}

A adoção de geotecnologias, especialmente os VANTs vinculados às técnicas de geoprocessamento e sensoriamento remoto, em projetos de engenharia tem-se popularizado rapidamente, tanto nos setores privados, como nos setores governamentais. Esta tendência se justifica essencialmente na economia de recursos financeiros, humanos e naturais, na rapidez de geração de resultados, no incremento da segurança de trabalho, e principalmente, por geração e coleta de dados confiáveis e de fácil compreensão, que retratam fielmente a realidade. Outrossim, permite monitoramentos mais abrangentes e irrestritos.

Salienta-se que as operações com VANTs exigem um conhecimento prévio para controle da aeronave, a fim de se evitar acidentes. Ademais, operadores de VANTs devem estar licenciados perante aos órgãos reguladores e atualizados das diretrizes de segurança.

Por se tratar de uma tecnologia relativamente nova, muitas das aplicações ainda estão em desenvolvimento. Recomenda-se futuros estudos nas áreas ambientais, como: VANTs capazes de coletar e analisar amostras de água e de ar para monitoramentos, VANTs acoplados com sensores que captam radiações infravermelho próximo e termais para análises que vão além do espectro visível ao olho humano e, por fim, VANTs acoplados com catapultas de sementes objetivando ações de reflorestamento mais eficientes.

\section{REFERÊNCIAS BIBLIOGRÁFICAS}

ASSOCIAÇÃO BRASILEIRA DE EMPRESAS DE LIMPEZA PÚBLICA E RESÍDUOS ESPECIAIS (ABRELPE). Panorama dos resíduos sólidos no Brasil 2015.

São Paulo, 2015. 92 p.

ASSOCIAÇÃO BRASILEIRA DE NORMAS TÉCNICAS NBR 8419. Apresentação de projetos de aterros de resíduos sólidos urbanos. Rio de Janeiro, 1992a.

BATISTA, H. P., SimOES, G. F., LANGE, L. C., AZEVEDO, R. F. d., \& CATAPRETA, C. A. A. 2010. Desenvolvimento de diretrizes para monitoramento 
geotécnico e plano de contingência/emergência em aterros sanitários. 147 p. Tese

(Doutorado) - Curso de Pós-graduação em Saneamento, Meio Ambiente e Recursos

Hídricos, Desa, Universidade Federal de Minas Gerais, Belo Horizonte, 2010.

Conselho Regional de Engenharia e Agronomia do Paraná (CREA/PR). Guia para

Elaboração de Projetos de Aterros Sanitários para Resíduos Sólidos Urbanos, volume III. 64 p., 2009.

DJI: Phantom 4 Pro. Disponível em: https://www.dji.com/phantom-4-pro. Acesso em: 30 mar. 2017.

EISENBEISS, H. The Potential of Unmanned Aerial Vehicles for Mapping. In:

Photogrammetric Week '11, Wichmann/VDE Verlag, Berlin \& Offenbach, 2011. 11 p.

LANGE, L. C.; SIMÕES, G. F.; LIMA, W. S. de CATAPRETA, C. A. A. ; Chiodi, Izabel C. . Projeto, operação e monitoramento de aterros sanitários. 120p. 2008. (Desenvolvimento de material didático ou instrucional - Guia de treinamento para profissionais em saneamento).

MOUTINHO, O; RODRIGUES, A; GONÇALVES, J. A, SOUSA, J.J; BENTO, R. Estudo comparativo de software fotogramétrico em diferentes ambientes com RPAS: Comercial vs. Open Source. In: Conferência Nacional de cartografia e Geodésica. Lisboa, 2015.

PAAR, P. Landscape Visualizations: Applications and Requirements of 3D Visualization Software for Environmental Planning. Computers, Environment and Urban Systems. Vol. 30,815-839. 2006.

SANTOS, A. R.; PELUZIO, T; SAITO, N. S. Spring 5.1.2 passo a passo: aplicações práticas. Mundo da Geomática. Alegre, ES: CAUFES, 2010. 153 p.

TOMMASELLI, A. M. G. Introdução. In: Fotogrametria Básica. Santa Catarina. UDESC, 2009. P.1-14. 